\title{
Global Pandemic, Translocal Medicine
}

\section{The COVID-19 Diaries of a Tibetan Physician in New York City}

\author{
Sienna R. Craig | ORCID: 0000-0002-6760-762X \\ Department of Anthropology, Dartmouth College, New Hampshire, \\ NH, USA \\ sienna.r.craig@dartmouth.edu
}

\author{
Nawang T. Gurung \\ Yulha Fund, New York, NY, USA \\ nawanggurung@gmail.com \\ Ross Perlin | ORCID: 0000-0003-1932-7057 \\ Endangered Language Alliance, New York, NY, USA \\ perlin@elalliance.org
Maya Daurio | ORCID: 0000-0002-5650-6604
Department of Anthropology, University of British Columbia, Vancouver, Canada maya.daurio@ubc.ca

Daniel Kaufman | ORCID: 0000-0003-0971-8409

Department of Linguistics and Communication Disorders, Queens College of the City University of New York | Endangered Language Alliance, New York, NY, USA

kaufman@elalliance.org

Mark Turin | ORCID: 0000-0002-2262-0986

Institute for Critical Indigenous Studies and Department of Anthropology, University of British Columbia, Vancouver, Canada mark.turin@ubc.ca

\author{
Kunchog Tseten \\ Department of East Asian Languages and Cultures, Columbia University, \\ New York, NY, USA \\ arurahealer@gmail.com
}




\begin{abstract}
This article analyzes the audio diaries of a Tibetan physician, originally from Amdo (Qinghai Province, China), now living in New York City. Dr. Kunchog Tseten describes his experiences during the first wave of the COVID-19 pandemic, in spring and summer 2020, when Queens, New York - the location where he lives and works-was the "epicenter of the epicenter" of the novel coronavirus outbreak in the United States. The collaborative research project of which this diary is a part combines innovative methodological approaches to qualitative, ethnographic study during this era of social distancing with an attunement to the relationship between language, culture, and health care. Dr. Kunchog's diary and our analysis of its contents illustrate the ways that Tibetan medicine and Tibetan cultural practices, including those emergent from Buddhism, have helped members of the Himalayan and Tibetan communities in New York City navigate this unprecedented moment with care and compassion.
\end{abstract}

\title{
Keywords
}

Tibetan medicine - New York City - COVID-19 - audio diaries - translocal care

\section{Introduction}

"It is Thursday, May 7, 2020. This morning, as I scanned the news, my thoughts returned to the conversations I have been having with my patients by phone," says Dr. Kunchog Tseten, a Tibetan medical physician who lives and works in the borough of Queens in New York City. He speaks these words in resonant Amdoké, the Tibetan variant of his homeland, Repgong, in the Amdo region of eastern Tibet that is part of China's Qinghai Province. Dr. Kunchog is recording his thoughts as part of a collaborative research project that combines longstanding work on language diversity in New York City with an urgent need to chronicle the impacts of this global pandemic on those who are at once marginalized - by virtue of immigration history, socioeconomic status, language, and race/ethnicity - and essential - by virtue of the vital work they do in and for New York, as well as the economic support they provide for families and communities around the world.

Later, Dr. Kunchog will summarize his audio diary entry in English, and these daily thoughts on his life as a Tibetan New Yorker and healthcare provider in 
the midst of the CoviD-19 pandemic will be shared. ${ }^{1}$ On this day, early in the course of two months of CoviD-19 diaries that Dr. Kunchog recorded for this project, he continues:

Many people in New York City are suffering from a wide range of physical and emotional conditions, exacerbated by quarantine and the ongoing pandemic. The most prominent of their complaints are anxiety, stress, and depression. These extraordinary circumstances deprive many people of the space and time they need to sustain an exercise routine. As a result, we are hearing complaints about muscle spasms, upper back pains, chest pain, and so on. When they come to me looking for suggestions to alleviate these pains, I have been asking them to do full body prostrations. If the patient is not religious, they may prefer to do physical movements such as yoga. Beyond movement, I have also been suggesting certain changes in their diets. For emotional problems including insomnia, it is good to take one teaspoon of nutmeg powder in bone broth before sleep.... Here I will share some ideas about the treatment of emotional conditions by parsing them not only as "disorders of the life-force wind," as Tibetan medicine commonly describes them, but sometimes as disorders of the phlegm, or as hidden fevers in the heart. After that I will also mention certain common formulae for their treatment.

Dr. Kunchog is a practitioner of what is called Sowa Rigpa in Tibetan, or the "science of healing." He has been a New Yorker for about a decade. With degrees in Tibetan medicine from China and Chinese medicine from the United States, as well as a deep foundation in Buddhist philosophy and classical Tibetan language, Dr. Kunchog's reputation as a careful and compassionate physician is well earned. His roster of patients spans not only the city but also the country and the world, from New York to Colorado, Kathmandu to Taipei. Most of the formulae he prescribes to patients are crafted in Qinghai and sent to him in New York. He provides care for people with chronic and acute conditions through in-person consultations and the direct application of external therapies (acupuncture, massage, moxibustion), supplemented by phone calls and social media platforms. WeChat-a communications lifeline for millions that was threatened by the Trump administration's diplomatic hostilities with China—supports what he describes as "Tibetan telemedicine."

1 Dr. Kunchog Tseten recorded his audio diaries in Amdo Tibetan and then provided his own English summary translations, which were then edited for style and grammar by Emily Luy Tan and uploaded with corresponding audio files to SoundCloud. Tseden 2020. 
The COVID-19 pandemic has upended and rearranged Dr. Kunchog's life, as it has for so many. The pandemic has introduced fear and uncertainty, shifting the elements of how this Tibetan physician practices. Dr. Kunchog's diaries provide an intimate perspective on Sowa Rigpa care under conditions of precarity, particularly (though not exclusively) for a population in New York City that can be considered "epidemiologically invisible,"2 given their complicated positions within "Asian" and "Asian American" demographics, and overrepresented in core essential worker categories, from nurses and home health aides to grocery store workers, childcare providers, and gig-economy drivers.

As illustrated in the diary excerpt above, Dr. Kunchog remains attentive to his patients at multiple levels: body, heart-mind, and community. In these diaries, we learn not only about his approach to CoviD-19-related symptoms and the possibilities for alleviation of those symptoms, but also about other types of suffering that Tibetan medicine addresses. These diaries do more than report on patient pulses, diagnostic practices, and therapeutic interventions; they help to humanize and ground what it means to care and heal across translocal ${ }^{3}$ environments in which practitioners and patients live at a moment

2 In coining this phrase, we are building on critical global/public health scholarship that recognizes how epidemiological metrics can "miss" medical events and demographic nuances as they relate to health outcomes (Adams 2015). This "invisibility" can occur with experiences that such methods are not designed to notice-nonreported pregnancy loss, for example. Although the inclusion of categories such as race/ethnicity, class, and gender in epidemiological studies are commonplace, such categorizations can overdetermine some elements of social difference as they bear on health outcomes, and miss others. In the case of Himalayan and Tibetan New Yorkers, given their relatively small population and the fact that they do not fit easily into one nation-state category, their representation in health statistics can easily, if unwittingly, disappear. Connecting mother tongue language data to health metrics is one way of pushing back against such invisibility, epidemiological and otherwise (Kaufman and Perlin, forthcoming). We hope to enable such data integration in the creation of the digital language map of New York City which is accessible through our website: languagemapping .nyc (Language Mapping n.d.).

3 We understand "translocal" to capture the ways in which movements of people, resources, and ideas, often couched within the frameworks of "transnationalism" or "globalization," do not neatly nor necessarily translate into patterns of assimilation nor do justice to the cyclic and circular nature of migration and diaspora (Craig 2020) or the ways that "the village" reflects and is reflected by "the world" (Herzfeld 2015). Rooted in scholarly discussions of mobility and identity in relation to nationalism and citizenship (Appadurai 1995; Banerjee 2011; Levitt and Glick Schiller 2004; Pfaff-Czarnecka and Toffin 2011; Shneiderman 2015; Etzold 2017), and building on studies that explore the "worlding" of Chinese medicine (Zhan 2009), translocality captures something of the close-knit networks of kinship and belonging that link places like Repgong and Queens in ways that are at once embedded in, but not fully defined by, transnational relations between the US and China, for example. Thinking translocally allows for nuance and specificity within the lived experiences of individuals such as 
of global health reckoning; they address questions of physician "self-care" and the role that routine mind-body practice as well as a Buddhist ethic of caregiving can play in staving off "burnout"; they locate this physician as a father and a husband, a friend, and a public intellectual; they reveal the importance of medical pluralism as a therapeutic strategy; and they point to the central role of language in the translation of medicine and science across societies and in the revitalization of cultural life in diaspora.

\section{Contextualizing the Diaries}

In spring 2020, the Queens neighborhoods of Jackson Heights, Elmhurst, and Corona were the hardest-hit area, by sheer coronavirus caseload, in the United States. These neighborhoods are among the most culturally and linguistically diverse on earth, including perhaps the largest concentration of Himalayan and Tibetan people outside of Asia. ${ }^{4}$ Dr. Kunchog's diaries are part of a broader community-based research effort to document, through forms of publicfacing scholarship and virtual ethnography, the experiences of Himalayan and Tibetan New Yorkers during the pandemic. His diary sits alongside nine other COVID-19 diarists, speaking and writing in an array of Himalayan and Tibetan languages, including Nepali, Dzongkha, Loké, Dölpo, Yölmo, Sherpa, and central Tibetan. These diaries chronicle diverse lived experiences, beyond headlines and statistics: a nurse comes down with the virus herself, an expectant mother faces pregnancy in the pandemic, a public health expert puts his training to use, a teacher navigates the new world of online classes. ${ }^{5}$

This multimedia record-nearly 500 entries totaling dozens of hoursoffers a unique portrait of the daily struggles faced by doctors, nurses, and essential workers; the immense pressures on elders, parents, and children under quarantine; and the new ways that Himalayan and Tibetan people are aiding not just their own communities but their neighbors and fellow New Yorkers. This project also includes a corpus of thirty interviews with community leaders, frontline healthcare workers, coronavirus patients in multigenerational families, and others; the collection and analysis of multilingual materials related to public health messaging and community responses, including

Dr. Kunchog, complicating what it means to be "home" or "abroad" in relation to daily life as well as medical practice, and refocusing experiences of Tibetan medicine not only on the global circulation of Tibetan medicines within markets for Asian pharmaceuticals (Kloos 2017) but on the interplay between practitioners, patients, and medicines in specific context.

4 Turin 2013; Sherpa 2019; Gurung et al. 2020.

5 Gurung et al. 2020. 
those circulating between America and Asia on social media; the mapping of COVID-19 mortality and morbidity statistics in relation to linguistic diversity in New York City; and the tracking of other scholarship and journalistic reporting on the impacts of the pandemic within Himalayan and Tibetan communities on two continents.

This research partnership builds on long-term collaborations between the authors of this article and members of the Himalayan and Tibetan New York community. Beginning with Nawang Tsering Gurung, a social entrepreneur and community mobilizer originally from Mustang, Nepal, the team brings together scholars of the Himalaya and Tibet, Mark Turin and Sienna R. Craig; Turin's doctoral student Maya Daurio, herself a geographer and geographic information systems specialist with Nepal experience; and linguists Ross Perlin and Daniel Kaufman from the NYC-based nonprofit Endangered Language Alliance. ${ }^{6}$ Together, we have leveraged existing networks of research associates and an ongoing language mapping project, ${ }^{7}$ itself emergent from an analog map of the Languages of New York and related research, ${ }^{8}$ as well as ethnographic research among Himalayan and Tibetan communities in New York City and home countries, to pursue this urgent and timely work. Our previous collaborations include Voices of the Himalaya, ${ }^{9}$ a video storytelling project launched in 2016 that documents the extraordinary diversity and vitality of Himalayan and Tibetan New York through oral history interviews in a dozen languages.

The other important context for Dr. Kunchog's diaries are the local, national, and global responses of Sowa Rigpa practitioners to COVID-19. As was the case when SARS COV-2 emerged in China in $2002-2003,{ }^{10}$ many such practitioners have responded to this public health crisis by referencing Buddhism and history ${ }^{11}$ and relying on Tibetan pharmacology. ${ }^{12}$ This has included exegeses on how to define and understand a "virus" in Tibetan medical terms, ${ }^{13}$ and other efforts at epidemic interpretation that move between biomedical and Tibetan medical ways of knowing. New forms of activism and engagement among

$6 \quad$ Endangered Language Alliance n.d.a.

7 Language Mapping n.d.; see also Daurio et al. 2020, for an article that discusses our language mapping work in relation to COVID-19 in New York City.

8 Languages of New York Map: Endangered Language Alliance n.d.b.; for the New York Times article on the impacts of such mapping work in relation to one Himalayan community in Brooklyn, see Freytas-Tamura 2020.

$9 \quad$ Endangered Language Alliance n.d.c.; see also Gurung et al. 2018.

$10 \quad$ Craig and Adams 2008.

11 Arya and van der Valk 2020; McGrath 2020.

12 Gerke 2020; Tidwell 2020.

13 Cuomu 2020. 
Sowa Rigpa practitioners have emerged in this moment, in some cases encouraging a renewed valuation of their expertise in the face of COVID-19 against biomedical hegemony and biological determinism, and, sometimes simultaneously, reinstantiating a sense of marginalization with respect to other Asian medicines, including Chinese medicine and Ayurveda. ${ }^{14}$ On the global stage, Tibetan medical responses to COVID-19 have included webinars in Tibetan and English on a range of topics including: the etiology and meaning of epidemics from Sowa Rigpa and Tibetan Buddhist perspectives, on-the-ground reporting about experiences of Tibetan and Himalayan people both in New York and in Tibetan areas of China, integrative healing techniques for preventative and restorative health care, and public health education efforts focused on Tibetan translations of topics such as biomedical disease etiology and novel coronavirus transmission pathways. Dr. Kunchog was a featured speaker in several of these events - the preparations for which he discusses in his diaries. ${ }^{15}$

Related to these interpretations of, and responses to, the pandemic through Sowa Rigpa frameworks, Himalayan and Tibetan New Yorkers have understood COVID-19 in culturally informed and linguistically situated ways. Various folk models of contagion, prevention, and treatment have been transmitted along with Covid-19. So too with the literal circulation of preventative medicoreligious amulets (rimsung) and powerful precious pills (rinchen rilbu). ${ }^{16}$ These actions reflect vocabularies of risk and protection informed by Sowa Rigpa and Tibetan Buddhism. They relate not only to the physical experiences of this novel coronavirus but also to mental health and emotional well-being. Beyond precious pills and medico-religious amulets, and as revealed through Dr. Kunchog's diaries as well as through virtual ethnographic interviews and social media posts, many Himalayan and Tibetan people have turned to other ingestible and external Sowa Rigpa therapies to help mitigate cases of COVID-19 and address ancillary health concerns. Tibetan physicians, including Dr. Kunchog, have been involved in treating patients who either tested positive

\footnotetext{
14 Banerjee 2020; Payyappallimana 2020; Sheldon 2020; Tidwell 2020; Tomar 2020.

15 These webinars have included a panel discussion on April 9, 2020, with distinguished Tibetologist Robert Thurman, Dr. Nida Chenagtsang, and others on Sowa Rigpa \& Covid 19 (Chenagtsang et al. 2020); an event on July 12, 2020, hosted by Columbia University's Weatherhead East Asia Institute that brought together Tibetan and Himalayan physicians, public health experts, scholars, and community activists, and in which three authors of this article (Craig, Gurung, and Kunchog Tseten) participated; a July 18, 2020, webinar organized by the Xining-based chapter of the World Federation of Chinese Medicine Societies, including scholars and practitioners from both the United States and Tibetan regions of China, and attended by more than 5 ,ooo individuals in China via live stream; and a series of webinars supported by the Kunde Institute (Kunde Institute n.d.) focused on Covid-19 and Tibetan medicine.

Gerke 2017, 2020.
} 
for COVID-19 or were suspected positive cases, within and outside New York. This therapeutic approach has been iteratively informed by ongoing discussions among Sowa Rigpa practitioners and institutions in India, Nepal, China, North America, and Europe about best practices and the development of new formulations to treat novel coronavirus symptoms. ${ }^{17}$ Such practices are referenced by Dr. Kunchog in his diaries.

It is also important to remember that these discourses and practices have been occurring within even larger political contexts of increasing Sinophobia. ${ }^{18}$ The "Kung Flu"-ization of COVID-19 as endorsed by politicians and circulated through social media has fueled all-too-human responses of ignorance and fear. Himalayan and Tibetan New Yorkers have not been sheltered from such anti-Asian sentiment; some have experienced this type of racism directly. At the same time, others in this community retain their own forms of mistrust about the Chinese state and Chinese individuals in relation to this novel and deadly virus, given many diasporic Tibetans' previous lived experiences. ${ }^{19}$ Such xenophobia has extended to the ways that nonbiomedical approaches to treatment and mitigation of COVID-19 symptoms-specifically those of Chinese medicine-have been discussed in popular news sources and scientific journals alike, at once exoticizing and minimizing their empirical basis for clinical efficacy. ${ }^{20}$ This bears on Tibetan physicians such as Dr. Kunchog, given the complex politics of recognition and support for Sowa Rigpa practice and pharmaceuticals in global and national contexts. ${ }^{21}$

In what follows, we describe the situation in which Dr. Kunchog has been living and working in Queens, during the initial surge of the virus in New York City. We outline the significance of Himalayan and Tibetan New Yorkers' epidemiological invisibility and describe some of the ways this diverse, resilient community has responded to the crisis. We then explore Dr. Kunchog's diary entries themselves, surfacing some of the themes outlined in the introduction. We conclude with reflections on what this form of "citizen ethnography" and vernacular attention to lived experience can do to broaden and deepen understanding of this pandemic and the role of language, culture, and Asian medicine therein.

17 See the article by Tidwell and Gyamtso in this issue (Tidwell and Gyamtso 2021). This case-study research has also been supported by a small grant from the International Association for the Study of Traditional Asian Medicine (IASTAM).

18 Lynteris 2020.

19 Some of this mistrust has been exacerbated by the recent arrest of an apparently ethnically Tibetan New York Police Department officer who has been spying on the exile Tibetan community on behalf of the Chinese government. See Holpuch 2O2O; Hong 2020.

20 Craig, Gerke, and van der Valk 2020a, 202ob.

21 Craig and Gerke 2016; Kloos 2017. 


\section{The Epicenter of the Epicenter}

Dr. Kunchog lives in the New York borough of Queens. His clinic is located in Jackson Heights. As of the first half of April 2020, this neighborhood, along with Elmhurst and Corona, had emerged as the epicenter of the COVID-19 outbreak, with over 11,000 cases and hundreds of fatalities recorded in a population of around 6oo,ooo. ${ }^{22}$ The surge of cases at Elmhurst Hospital quickly became the city's "number one priority," according to NYC mayor Bill DeBlasio. ${ }^{23}$ Central Queens is among the most culturally and linguistically diverse urban areas on earth. ${ }^{24}$

The Himalayan and Tibetan communities of New York are centered here. Approximately 40,000 immigrants from Nepal, Bhutan, northern India, and Tibetan areas of China live in these neighborhoods, as well as in other hardhit neighborhoods in Brooklyn. One of the first deaths in the city was that of Anil Subba, a Nepali immigrant and Uber driver in his forties living in Jackson Heights; one of the earliest examples of collective community action was the formation of the Urgent Nepali Aid Network for Covid19. ${ }^{25}$ On April 2, 202O, members of just the Nepali portion of the Himalayan community were reporting a minimum of 400 people seriously ill and six in intensive care units, with cases growing. An estimated 500 members of the Tibetan Nurses Association of New York and New Jersey, including many working at Elmhurst Hospital, organized and deployed resources not only for frontline healthcare workers but also for general community members. ${ }^{26}$ Tibetan and Himalayan social service organizations engaged in heroic efforts to support the city's hospitals and healthcare workers by setting up a community kitchen. These are only a few examples of the ways this marginalized and diverse new immigrant community - one that is highly internally organized and communityminded-has responded to the CoviD-19 crisis.

In this case, as throughout history, epidemic disease is far from a "great equalizer." ${ }^{27}$ Rather, diseases such as COVID-19 impact individual bodies, communities, and the body politic unevenly. Socioeconomic inequality, including

\footnotetext{
22 Buchanan et al. 2020; see also Correal and Jacobs 2020.

23 Stein and Kim 2020.

24 Turin 2012.

25 Non-Resident Nepali Association National Coordination Council USA, New York Chapter n.d.

26 Tibetan Nurses Association of New York and New Jersey 2020.

27 See Hanson 2010; Mukharji 2012; Mason 2016 for social histories of epidemics in Asian contexts.
} 
immigrant status, ${ }^{28}$ reveals itself in differential access to public health infrastructures, uneven health outcomes, and underrepresented deaths. ${ }^{29}$ Immigrant groups in cities such as New York are often exponentially vulnerable in epidemic times. ${ }^{30}$ The impacts of CoviD-19 on these people have profound ripple effects on home communities, particularly when remittances play a vital role in family livelihood strategies and national GDPs. ${ }^{31}$ Himalayan and Tibetan New Yorkers often commute long distances, mostly on public transit, to do frontline service work as nurses, nannies, food service workers, construction workers, and drivers-the latter a much larger occupational niche for this community than for other Asian immigrants and a profession that has seen significant numbers of CoviD-19 deaths. While, in some cases, Himalayan and Tibetan New Yorkers were able to access health care, including hospitalization for severe illness, in other cases this was not possible. Several of the deaths from CoviD-19 within this community occurred at home-within cramped apartments shared with many family members. In one case, the individual who passed away worked at a grocery store and was instructed to come to work, even though he had begun to feel sick. He was undocumented and supported his family in Nepal. The combination of socioeconomic insecurity, immigration status, and language and cultural barriers served to hasten this person's decline, and create new forms of suffering and confusion for family members both in New York and Nepal after his death.

And yet, this death was not counted in official covid-19 statistics. Given the overwhelmed state of the city's health services and the individual's immigration status, no postmortem coronavirus test was performed and the coroner's report simply recounted that this individual had died of "recent, acute flu-like symptoms." Beyond the logistical challenges posed by a public health infrastructure under siege, accounting for the epidemiological impacts of COVID-19 on Himalayan and Tibetan New Yorkers is made more challenging by the fact that they do not fit easily into demographic accountings of disease impacts by race, ethnicity, or country of origin. Akin to the ways that the novel coronavirus that causes CoviD-19 remains "invisible" to the naked eye, including extensive asymptomatic transmission, the impacts of this disease on Himalayan and Tibetan New Yorkers can be obscured by their relative invisibility in hyperdiverse immigrant New York. They represent a relatively small population within much larger "Asian" immigrant categories (Indian, Pakistani, Chinese,

\footnotetext{
28 Jordan 2020; Lopez and Holmes 2020.

29 Hogan 2020.

$30 \quad$ Bonifacio 2020; Ross, Diaz, and Starrels 2020; Ruiz-Grossman 2020; Venugopal 2020.

31 Akram 2020; Gill 2020; Sharma 2020; Suleymanova 2020.
} 
for example); at times, their positions as refugees and asylum seekers, often effectively stateless, further complicate how they are counted.

The epidemiological invisibility of Himalayan and Tibetan New Yorkers is two-way, with language access being a central challenge as well. ${ }^{32}$ Officials and policymakers lack the capacity to comprehend the toll in, and relay critical information to, communities of which they are unaware, while communities themselves may fail to receive information on time, access state social services such as unemployment, communicate with healthcare providers if a loved one is sick and/or hospitalized, and comprehend what terms like "social distancing" or "quarantine" mean. Himalayan and Tibetan New York-based social service organizations mobilized quickly to create materials in relevant languages in line with biomedical public health advice. The Tibetan Nurses Association of New York and New Jersey, for example, set up emergency hotlines to answer questions related to CoviD-19; others mobilized through social media to explain how to register for unemployment benefits and created support systems for weekly filings for those who could not do this themselves. Community members paid attention to the ways that information was traveling between New York and "home" communities in Asia, in some cases leveraging public health information in relevant languages from across the world and deploying it in New York neighborhoods. This took place even as linguistic representation and direct support for this community from city and state social service agencies remained minimal to nonexistent.

We now turn to several of the key themes that emerge from Dr. Kunchog's diaries themselves - themes that are at once attentive to, and yet move beyond, the novel coronavirus.

\section{CoviD-19 Therapeutics}

Dr. Kunchog begins the diary with reflections on CoviD-19's causes and conditions from a Tibetan medical perspective as well as selective reflections on his coronavirus patients. Dr. Kunchog's in-person consultations stopped altogether through lockdown. He followed public health guidelines and did his best to protect himself against COVID-19 exposure, relying more than usual on telemedicine. If patients described any signs or symptoms of the coronavirus, he diagnosed them solely through telemedicine. In total, he mentions seeing approximately twenty COVID-19 cases during the two months that he kept his diary, many of them for repeated consultations and sustained treatment through the course of the disease and beyond. 
At the start of his diary, on May 1, 2020, he reflects on three patients-none of whom were able to receive a COVID-19 test but who were presumed positive. "I saw three patients just before lockdown orders," Dr. Kunchog begins, before describing their symptoms: high fevers, difficulty breathing, headache. Some were having trouble taking his Tibetan medical pills due to respiratory stress. All three of these patients were "American," a descriptor Dr. Kunchog uses not to indicate citizenship but rather to point out racial and ethnic differences with his Tibetan or Himalayan patients, in New York or elsewhere. One of these had been his long-term friend and patient whom he first met through Facebook and whose entire family had now contracted the coronavirus. He prescribed a month of medications and told her that it may take two weeks to show an effect. "She took the pills diligently and after ten days reported that her headache and fever were getting much better. She was not taking any other medications - just my herbal pills." Dr. Kunchog goes on to describe other initial COVID-19 patients including a husband and wife, who had not been formally tested but based on exposure were presumed positive. He sent them two months of medicine and they also reported a positive impact. "Although I cannot say that my pills can cure CoviD-19," reports Dr. Kunchog, "it is clear [to me through my clinical experience] that Tibetan medicine is able to allay and control the symptoms." Later, he notes that "given the advised formulae and materials are properly prepared, our medicine can definitely help remedy pandemic diseases such as this."

On May 8, 2020, Dr. Kunchog describes the specifics of a COVID-19 case in a Tibetan couple and their child. They had been sick for nearly six weeks and had suffered from tightness in the chest, cough, and fever. Their young daughter had not been diagnosed with coviD-19 but had serious diarrhea and no appetite. Dr. Kunchog sent the family several formulas, including one that he ordered from Amdo and that was produced as COVID-19 was cresting in Wuhan, China. He notes that many of his Tibetan colleagues in China had not actually seen a coronavirus patient in person, but that they were practicing telemedicine and sending formulas from Tibetan areas to other parts of China.

As a pivot from these particular cases, at various moments in the diary Dr. Kunchog describes the ways that Sowa Rigpa classifies, understands, and addresses epidemic diseases, according to the third tantra of the Four Tantras (rgyud bzhi), the foundational text for Sowa Rigpa theory and practice. As has also been reflected in writings about the novel coronavirus from the perspective of Chinese medicine, ${ }^{33}$ Dr. Kunchog describes different progressive stages of the disease, along with recommendations about how to "ripen" the early fevers and address other issues through medicines, diet, and behavior change. 
He indicates specific formulae to be used at different stages, as the disease moves from the early phlegm (bad kan) stage, through the bile (mkhris pa) phase, and then into the blood (khrag) phase. He notes that it is helpful for the patient to have a routine checkup when the disease has entered its final stage, to assess how this illness has impacted overall health and bodily function. Later, as he reviews the Four Tantras and other classical medical texts, he speaks of the empirical knowledge of epidemics presented in these sources, a therapeutic process that first blocks the channels [of transmission], then kills the nad $d u g$ (a Tibetan gloss for "virus"), reduces the fever, and then consolidates the treatment, after which formulae are given that help clean the system.

On May 10, 2020, Dr. Kunchog describes a CoviD-19 patient who, while testing negative for the virus and showing antibodies, was still having heart rate spikes. She was worried because her biomedical doctors could not explain this phenomenon. Dr. Kunchog uses this specific example as a way of delving into a general discussion of epidemic disease etiology, connecting her symptoms of heart rate increase to the final stage of the disease.

We can see the final stage is the best time to fight the wind $(\text { rlung })^{34} \ldots$ During this final stage it is essential to balance wind with nutritious foods such as bone broth, to reduce exercise, and to not take on any stress ... to balance the pervasive wind which is located in the heart organ. When this type of wind is out of balance, the heart rate will increase.

Dr. Kunchog postulates that this is the reason for the patient's heart rate spikes, and he sends her rlung formulae to address this issue.

In another illustration of this relationship between general therapeutics and specific COVID-19 cases, on May 12, 2020, Dr. Kunchog talks about a couple, both of whom had contracted coviD-19. While the husband recovered, the wife, whose underlying state of health is generally worse, had continued to "struggle with breathing and a sense of fever in her body even though a thermometer does not register a temperature." Dr. Kunchog explains that he has been treating her with eaglewood ( $a$ gar) formulae and two other medications to address some of these root issues to do with lung and respiratory problems but also her underlying digestive weakness, and then notes that he is tuning her prescriptions according to her bodily constituents. Describing the Sowa Rigpa logic of diagnosis based on the three "dynamics" (nyes pa; often mistranslated as "humors"), Dr. Kunchog summarizes, "This is a basic treatment principle in Tibetan medicine. If the pills we give are meant only to allay the

Note that there are different kinds of rlung. 
symptoms, the underlying disease will tend to recur chronically, bothering the body, never resolving."

On May 13, 2020, Dr. Kunchog treats a patient, now recovered from COVID-19, but suffering from problems related to his employment as an essential worker at Whole Foods, the grocery store chain. He sees this patient in person, offering him an acupuncture treatment for lower back pain, which often accompanies such work, and prescribing formulae to address his underlying weakened kidneys - the result of laboring in cold environments all day long - and to address lingering weaknesses from COVID-19. On May 27, 2020, a similar dynamic emerges with a CoviD-19 patient, now testing negative, who reports back pain and other forms of weakness since he was discharged from the hospital two weeks prior. Although this patient's bodily constituents are distinct from the May 12 and May 13 patients, this individual, too, is diagnosed with another variation of a wind disorder-one that Dr. Kunchog describes as manifesting in part through bone and joint pain that can occur in the final stage of epidemic disease. "During this period, the disorder has to be treated with tremendous care, as if it was one's own son." He decides this patient is best treated with a shift in his prescription as well as with external therapies: a type of moxibustion (hor me), acupuncture, cupping, and massage with nutmeg oil.

The following day, Dr. Kunchog describes another patient, from Manhattan, who is now testing negative for COVID-19 but has been continuing to suffer from diarrhea. After discussing this long-term patient's constitution, he then pivots toward a general observation:

After the treatment of the flu or epidemic fever diseases, it is quite common to have diarrhea because the herbs cleanse the virus or inflammation and it is voided in this manner. Some of the herbs are a little strong and may act as a laxative. We often have to follow up with a treatment for this kind of diarrhea after treatments for flu or other contagious diseases. We have learned from cases of this type that the heart of most Tibetan medicine treatments is the protection and maintenance of the digestive system.

The pattern of digestive issues coming on the heels of the most acute part of coronavirus infection is a theme that runs through the diaries, appearing in several places, including on June 16,2020 , again with the couple that he treated a month prior. ${ }^{35}$

35 In several cases, Dr. Kunchog reports that people he has treated who were presumed positive for coronavirus but tested negative were individuals whose primary symptoms were gastrointestinal. This phenomenon has been reported elsewhere (Han et al. 2020). 
We observe a discursive rhythm in the diaries of moving from particular cases to general principles, as patients move from an initial CoviD-19 diagnosis to testing negative but still not being well. On June 2, 2020, Dr. Kunchog details another such case - this time a CoviD-19 patient, now testing negative, who is still suffering from a range of symptoms, including difficulty breathing, profuse sweating, and a frequent cough. Although he explained his symptoms to his biomedical physician, the physician is solely focused on his now-negative coronavirus test results. ${ }^{36} \mathrm{Dr}$. Kunchog, by contrast, sees these enduring symptoms as relating to a "turbid hot disorder" that has resulted from a cascade of dynamic imbalances as manifested through the body's efforts to respond to the virus. He prescribes decoctions, external therapies, dietary prescriptions, and ingestible formulae.

In some cases, Dr. Kunchog is left not treating CoviD-19 directly, but rather the mental and physical fallout from fear of the disease. He notes many cases of patients who have not contracted the virus but who are so scared of it that they experience other health effects such as depression, anxiety, insomnia, and musculoskeletal problems that have arisen from being confined to small living quarters and not getting exercise. On June 7, 2020, for instance, Dr. Kunchog notes, "I saw nine patients today between gam and 3pm. Most of them complained of anxiety and stress on account of the pandemic. Even some of the younger patients were exhibiting life-sustaining wind disorder," a diagnosis that is much more common in elderly people.

People have such fear of the virus that they do not go outside. Our day-today life has changed so much, and people are having a hard time accepting it. We need to spread the word about the benefits of meditation so that they will learn. Otherwise, postpandemic syndrome will cause problems for many.

This concept of "postpandemic syndrome" reflects a form of trauma that many New Yorkers and others are carrying, even as we continue to live within the boundaries of a pandemic that, while geographically and episodically constrained, is far from over. ${ }^{37}$

On June 17, 2020, Dr. Kunchog elaborates on these dynamics, noting that while many Tibetan and Himalayan people have the mental and emotional

36 We recognize that this representation of biomedical knowledge/practice can be contested and also that scientific understandings of "chronic" CoviD-19 have expanded significantly since spring/summer 2020 .

Consider the resent resurgence of disease in New York, particularly in Brooklyn and Queens: Goodman 2020. 
fortitude to deal with pandemic stress, in part due to Buddhist practice"prostration, chanting, meditation"- the younger generations are suffering more in part because they "do not have strong faith nor religion and are always watching TV or playing games to pass the time." He reflects on this in contrast to the ways that he has used this time of forced slowdown and time with family. "Since the pandemic, I cherished this serious situation to teach Tibetan to my son," he notes on June 15, 2020. In addition to using the period to instruct his children in their mother tongue and culture, on June 10, 2020, Dr. Kunchog writes: “I didn't waste the quarantine period. I studied a lot and read many classical Buddhist books. I also accumulated a lot of virtue and merit through chanting, meditation, and helping patients during these hard times."

\section{Healing beyond Coronavirus}

Across the United States and the world, we have only begun to see the impacts of the COVID-19 pandemic on basic primary care, including vaccinations; management of chronic diseases such as asthma, chronic obstructive pulmonary disease, and diabetes; care for pregnant and delivering mothers; support for the frail and elderly; mental health; and palliative as well as end-of-life care. ${ }^{38}$ Specialized and time-sensitive medicine, including oncology ${ }^{39}$ and the treatment of autoimmune disease, ${ }^{40}$ have been interrupted. In the United States, structural inequalities tied to race/ethnicity, class, immigration status, housing conditions, and food security are exacerbating the impact of this virus and revealing the need for transformative change to our healthcare system. ${ }^{41}$ Rates of mortality and morbidity among minority and otherwise marginalized populations are orders of magnitude higher than their white and/or wealthier counterparts. ${ }^{42}$ This is true in many places, including New York. Neighborhoods such as those where Himalayan and Tibetan New Yorkers live, where there are higher rates of chronic disease and a higher proportion of black, brown, and low-income residents, have disproportionately higher rates of CoviD-19 and, historically, much poorer access to primary care. ${ }^{43}$

Within this context, Dr. Kunchog's commitments to his patients' overall health and well-being — not just their battles with the novel coronavirus—are

38 Pettigrew, Kumpunen, and Mays 2020; Williams and Tsilligianni 2020.

39 Tsamakis et al. 2020.

40 Grange et al. 2020.

41 Slavitt 2020; Behbahani et al. 2020.

42 Correal and Jacobs $202 \mathrm{O}$.

43 Jordan and Oppel Jr. 2020 detail such disparity for Latino communities living in close proximity to Himalayan and Tibetan New Yorkers. 
important to acknowledge. In no way does he stop providing primary and specialized care during the pandemic, whether patients live in his neighborhood in Jackson Heights or in other cities or countries. He continues to treat individuals, many of whom have been his patients for months or years, through a combination of clinic-based visits, house calls, and telemedicine. The health issues that he is prepared to address as a Tibetan medical practitioner are wideranging, from digestive problems to joint and musculoskeletal issues like frozen shoulders and herniated discs, from cancer therapy to chronic migraines. Dr. Kunchog's treatment strategies reflect his multidimensional training in both Tibetan and Chinese medicine. Sometimes he writes in general terms about the causes and conditions of disease.

"I have been seeing patients here for almost twelve years now," he notes early on in the diary (May 2). "Diseases are also very connected to diet. Americans like to eat salad and drink cold water and cold beer. Tibetans and people from the Himalaya like a very heavy dinner. Both types of diets result in a digestion problem ... The most important thing is for the patient to change their lifestyle and diet causing the symptoms." With respect to emotional conditions that biomedicine might gloss as mental health disorders, Dr. Kunchog acknowledges them as connected to the life-force wind, as Sowa Rigpa commonly describes them, but he also connects them to phlegm (bad kan) and "hidden fevers of the heart." When discussing his long-term treatment of people with depression, for example, he notes that the seat of phlegm disorders is in the crown chakra. "The Four Tantras describes the brain as 'an ocean of nerves," he writes, noting that he has had good results in treating patients who have been diagnosed with clinical depression by biomedical practitioners in multidimensional ways: addressing both the life-force wind and underlying phlegm disorders.

Dr. Kunchog's diagnostic and therapeutic strategies address mind-body dynamics and embody the principles of medical pluralism. Consider how he writes about one class of "essential" workers that he treats:

In my clinical experience, Uber and taxi drivers often have chronic lower back pain as well as frequent urination when they are at home. Their pulses tend to be very sunken and deep. Their urine is turbid with sticky bubbles, and there is a greater accumulation of sediment than one might otherwise expect. What we call the left chi pulse is deeper than the right. They often suffer from pain in the lower back and hip area ... I would diagnose a deficiency of the descending wind. You see, the descending wind is located in the lower abdomen and secret chakra—negative emotions like nervousness and fear are also related to this type of wind. Of course, taxi drivers in NYC have much to be anxious about and their work often 
gives them cause for brief, intense bursts of fear ... Not only that, but they have to hold their urine for long periods of time. Treatment with a combination of acupuncture and Tibetan herbs can quickly reduce their pains. Frequent urination can mostly be diagnosed as prostate issues and can be treated with Tibetan medicines if the disease has not become chronic. (May 9, 2020)

Here, we see evidence of his Tibetan medical training and approaches to healing rooted in Chinese medicine as well as an appreciation for biomedicallyoriented understandings of pathology and physiology.

In other moments, Dr. Kunchog toggles between generalized assessments and patient specifics. On May 10, 2020, for example, he describes a house call with a female patient suffering from acute stomach pain and severe headache. "Her voice was almost unrecognizable," he begins - a nod to how well he knows his patients. Dr. Kunchog describes his past prescription practices, her regular dietary habits, and the dynamics of her current pulse in comparison with past moments. The specifics of her case become a moment to explain how Sowa Rigpa understands the relationship between diet, digestion, and headaches in contradistinction with a biomedical diagnosis of migraines. "I found that when Western medicine gives a diagnosis of migraines," he notes, "the headaches in question are often related to phlegm. I have been able to treat some of my patients who suffer from chronic migraines with formulae routinely used in the treatment of phlegm disorders." Dr. Kunchog goes on:

Lab tests and other Western diagnostics can be insufficient to treat certain conditions (for instances those often called "chronic" because they are not well understood) to cure underlying disorders. Certainly, lab tests and diagnostics give us important information, but one must assess the causes of each patient's disease carefully, on an individual basis. This should be done through the prism of the patient's constitution and analysis of pulse and urine, which reveal the quality of the disease. Without knowing the quality of disease, it cannot be properly treated.

In this case, the patient's dietary proclivities as well as Dr. Kunchog's sustained attention to her general constitution exemplify his approach to primary care.

When it comes to translocal care for long-term patients, Dr. Kunchog notes that many of these individuals suffer from cancer or autoimmune disorders: a breast cancer patient in Florida; a cervical cancer patient in New York; a liver cancer patient in Virginia; a patient in Taiwan with anxiety, depression, and hypertension. Dr. Kunchog remains attentive to patients back in Tibet, 
speaking mostly through WeChat with those whom he has treated previously or who have been referred to him by friends and relatives in Qinghai: a nomad suffering from retinal vasculitis and an old high school classmate suffering from keratitis, whose eye problems reflect the Tibetan saying, "The eye is the flower of the liver."

Throughout the diary, we read of Dr. Kunchog making trips to the post office to send packages to patients or receiving shipments of formulae for his own use. ${ }^{44}$ He notes that part of why these therapies seem to work well is that they are tailored to the individual constitutions of the patients. While Sowa Rigpa understands "cancer" in ways that at once dovetail with and are distinct from biomedicine, Tibetan medical formulae help not only because of a focus on the "root" of the disorder but also because "our concern is for the health of the whole being, which in turn supports their cancer recovery" (May 22, 2020). Still, patients die. On June 3, 2020, for example, Dr. Kunchog receives a call from the sister of one of his ovarian cancer patients, informing him of her death. "I felt very sad. I prayed to the Medicine Buddha."

In one remarkable example of translocal medicine on May 18, Dr. Kunchog describes receiving a WeChat message from the son of a patient in Nepal who had been diagnosed by a biomedical Nepali physician with a motor neuron disease three months prior. Dr. Kunchog describes how the son reached out because his mother wanted to be treated with Tibetan medicine. He helped the son secure a precious pill (Coral-70) from a specific producer in Lhasa, and then also connected this patient with a Kathmandu-based Tibetan doctor who was able to treat her-according to Dr. Kunchog's teacher's unique specifications - with a form of moxibustion. "This way of applying moxa is different than usual, and there are a few herbs that need to be mixed with it ... Since receiving this moxa treatment, her speech is slowly getting clearer and faster, her mind is clearer, and she can walk without a cane."

Overall, the diaries reveal a physician who is concerned about COviD-19 and sees this acute crisis within a much broader vision of the causes and conditions that produce ill-health. At the same time, Dr. Kunchog is immersed in the needs of individual patients, particularly those who are facing this pandemic from positions of socioeconomic precarity—as immigrants, as non-English speakers, as essential workers.

44 The formulae from Qinghai are sourced from a variety of places, principally Good Manufacturing Practices-certified state pharmacies and private factories with which Dr. Kunchog has enduring connections. 


\section{Care and Connection}

Dr. Kunchog's diaries reveal the rhythm of days. There is certainty and routine to what he shares, even within the uncertainty of a global pandemic. Nearly each diary entry begins with a form of religious practice - a daily meditation, prayers to the Medicine Buddha, the reading of sutras. These opening notes are often followed by attention to family members and patients who live far beyond New York City, as well as time focused on the latest coronavirus news, in New York and beyond. We learn about Dr. Kunchog's video chats with his elderly parents in Repgong, his conversations with patients and friends around the world, and his efforts to use this altered time to the best of his abilities, with his family and for his Buddhist practice.

I had breakfast with my two lovely children. After breakfast, I helped my son with his morning classes and completion of his school assignments. (May 27, 2020)

This morning I woke up earlier than usual after listening last night to the Compassion Buddha empowerment bestowed by His Holiness the Dalai Lama ... I am very excited to have the opportunity to hear teachings from His Holiness ... He is a master meditator, philosopher, scientist, and revolutionary (May 29, 2020)

Even so, he is forthright about the challenges he faces: balancing the needs of his patients with his wife's work, studies, and childcare needs; the stress prompted by his son's online learning; his many responsibilities and the obstacles they pose to maintaining his own physical and mental health; fluctuations in his number of patients during lockdown (and related impacts on his income, although this is not something that he discusses directly, in line with a sense of Sowa Rigpa moral economy and the standard ethics of Tibetan medical practice) and the economic and professional fallout from an unexpected building fire at the site of his clinic. On June 4, he speaks with a mix of fatigue and optimism:

I can't rest much at home because I need to teach Tibetan to my son. He is $5^{1 / 2}$ years and can read the basic words. I have been teaching him calligraphy and reading short stories ... I never skip the schedule even if we are exhausted ... The best way to preserve your own culture and language is to keep it alive through your children. 
We learn about how Dr. Kunchog takes up running and walking in his neighborhood, as well as Tibetan yoga and prostrations, as ways to address his own well-being. Through the diaries, we travel with Dr. Kunchog and his family as they seek out nature in upstate New York and Connecticut as time and public health precautions allow. We are invited to witness the ways that Dr. Kunchog combines his Sowa Rigpa and Buddhist training, his capacities to translate between medical systems, and his commitment to his community. Nowhere is this clearer than in the story of one of Dr. Kunchog's dear friends who suffers a series of distressing medical experiences and diagnoses.

On May 19, 2020, Dr. Kunchog woke up early, concerned about a close friend who had been hospitalized two days prior with complications from heart disease. Transferred from Elmhurst Hospital, in Queens, to Mt. Sinai Hospital, in Manhattan, the friend was at first given a diagnosis of pericardial effusion and treated accordingly. "All night I was worried about his recovery and I didn't sleep very well." He goes on to say, "I had read his pulse a couple of times but failed to make a correct diagnosis. I didn't find any problems in his heart, only in his liver and stomach pulse." Dr. Kunchog notes that although he missed this problem with his friend's heart, the concerns over his liver and stomach were accurate. The Mt. Sinai physicians discovered an abnormality on his liver requiring a biopsy to determine if it was malignant. Soon thereafter, he was scheduled for liver surgery.

Over the next six weeks, Dr. Kunchog takes on many roles. He helps this friend as he is diagnosed not only with stomach cancer but also with a rare form of infection from a tapeworm, carried in his body for many years, from Tibet, that has impacted his liver as well. On June 10, 2020, they make a hospital visit together.

The doctor said it was the first time he saw a case like this. They are going to write an article about it. From his blood, they found a specific parasite that normally comes from dogs ... an infection with the larval stage of the dog tapeworm Echinococcus granulosis. Having the surgery, he learned his liver was infected and perfused to his diaphragm. Then the fluid accumulated in the heart area. First, he took fluid from the heart. Then he did liver surgery. He showed us a liver model and said that one part of the liver took over. After the liver surgery, he sent him to the stomach cancer surgeon. He said it was a complicated case. He ordered a CT scan every three months.

In this and other moments, we see Dr. Kunchog in the position of patient advocate and medical translator (his friend does not speak English), home caregiver and cook, counselor and friend. He contacts his friend's only relatives 
living in the US, in Maryland, to coordinate care. He buys lamb and organic vegetables, prepares dumplings, spends the night on his friend's couch on many occasions, and conducts religious practice on his friend's behalf. We learn from Dr. Kunchog that this friend has suffered personal losses-his wife left him and then he began drinking heavily — and also that he is a man of intelligence, skilled as a cook, a painter, and a construction worker. "Life is hard to predict," Dr. Kunchog notes that day, reflecting on his friend's situation. "It is vitally important for each of us to take care of our health."

\section{Conclusion}

Dr. Kunchog's diaries provide insight into the course of the pandemic. At various moments in the diary, he acknowledges that some patients are coming to see him because they are fearful of going to a clinic or hospital due to COVID-19 risk, although they might "normally" have sought biomedical care first; in other moments, he describes the importance of integration between Sowa Rigpa and biomedicine, not only for coronavirus but for other health issues. These views do not seem to have been fundamentally changed by Covid-19, but Dr. Kunchog makes an effort to illustrate the role that Sowa Rigpa can play in addressing epidemic infectious disease as well as noncommunicable and chronic disorders.

The diary speaks to how a Sowa Rigpa practitioner navigates his ethical responsibilities to patients alongside his obligations to family and friends; it shows how, as a practitioner of medicine as well as Buddhism, he maintains his own well-being, in the service of these larger goals. Dr. Kunchog describes such circumstances while acknowledging externalities beyond his control-from the fire in his clinic building and the need to move his practice in the midst of this public health crisis, to the ways he finds joy, purpose, and gratitude through the pandemic. Dr. Kunchog sees benefit in added time to read sutras and to instruct his son in Tibetan, even as he recognizes the massive impacts that the pandemic is having on so many people and envisions the impact that "postpandemic syndrome" will have on his patients and the broader communities he serves.

Finally, Dr. Kunchog's diary raises compelling questions about tone and audience. ${ }^{45}$ The diary entries neither assume previous knowledge nor shy

45 We have not, as yet, undertaken an in-depth sociolinguistic analysis of the relationship between the Amdo Tibetan audio diaries and the English summaries, although this would certainly be a fruitful avenue for further scholarship. 
away from the specifics of social life, as experienced by this Tibetan physician. Often, he writes for a broad public:

Aspects of the environment we live in such as the weather affect our body and can cause disease. For example, we are living in New York City, which is located by the ocean and a river and is very cold in the winter. Here, there are many people suffering from arthritis as a result; not only people who are American-born but also people from the Himalayas and elsewhere. (May 2, 202O)

The heart of most Tibetan medicine treatments is the protection and maintenance of the digestive system. (May 14, 2020)

In this way, Dr. Kunchog's thoughts and experiences serve as a primer in Tibetan medical theory and practice, offering comparative accounts of biomedical and Tibetan medical approaches to health and disease. They are an exposition of how and why Sowa Rigpa and Tibetan cultural practices offer something unique and precious to the world-including, but not limited to, making sense of and responding to a global pandemic. "Our lives are impermanent as a drop of dew balanced on a blade of grass," Dr. Kunchog reminds us (June 22, 2020).

When taken together with the work of other diarists - themselves teachers and healthcare workers, parents, students, and Covid-19 patients-our corpus of interviews with community leaders, and additional community-based research, Dr. Kunchog's diaries make clear that no Himalayan or Tibetan New Yorker has been untouched by a crisis that is not simply a deadly virus but also a mental health epidemic, an economic emergency, and an ongoing period of unprecedented and protracted uncertainty. With the virus having ebbed in New York over the summer, more than 46o,ooo confirmed cases and 25,000 deaths as of early January 2021, the toll of the virus itself on the Himalayan community is as yet unclear, as the caseload rises again. ${ }^{46}$ What is certain is that deaths have touched the community and that most people know or are related to people who have fallen seriously ill; many have been sick and recovered at home without being diagnosed; others were uncertain if they have been infected with COVID-19; some may have known that they were infected but felt uncomfortable admitting it, given the cross-cultural capacity to associate stigma with infectious disease; ${ }^{47}$ and many Himalayan and Tibetan New

$46 \quad$ Almukhtar et al. 2021.

47 This issue of stigma related to covid-19 was not an issue that Dr. Kunchog's diaries highlighted; however, this issue was mentioned in several of our other diaries and interviews. 
Yorkers remain understandably anxious about their and their family's social and economic futures, even if they have avoided contracting or have recovered from the virus.

In Dr. Kunchog's diaries, as well as the diaries of others involved in this research project, we see a community capable of extraordinary endurance and resilience. This is evidenced by: an intensification of already close family and community ties and religious practices, widespread adherence to and respect for public health measures, creative mutual aid efforts that have included individual checkups on the ill, internet-based programs for isolated elders, organized efforts to navigate complex government services for which little non-English language help is available, and more. Indeed, beyond organizing and taking care of its own, Himalayan and Tibetan New Yorkers have been going much further as healthcare professionals, essential workers, service providers, and simply as neighbors. Along with so much else, these diaries testify to the growing strength of a New York City community and a focal point of the global Himalayan and Tibetan diaspora. We sincerely hope that Himalayan and Tibetan New Yorkers will weather the second wave of community transmission with as little suffering as possible.

\section{Acknowledgments}

This research was assisted by the Social Science Research Council's Rapid-Response Grants on Covid-19 and the Social Sciences, with funds provided by the Social Science Research Council, the Henry Luce Foundation, the William and Flora Hewlett Foundation, the Wenner Gren Foundation, and the MacArthur Foundation. In addition, the authors gratefully acknowledge support for this research from the Peter Wall Institute Wall Solutions Grant (University of British Columbia), Dartmouth College's Office of the Provost SPARK Award, and the Claire Garber Goodman Fund, Department of Anthropology, Dartmouth College. We are grateful to the editors and peer reviewers for supportive and helpful comments, to Dartmouth students Emily Luy Tan and Katherine Fearon for their editorial assistance on the diary summaries, and to Julia Schillo for her assistance with copyediting the final manuscript for submission.

\section{About the Authors}

Sienna R. Craig is a professor of anthropology at Dartmouth College. Her work focuses on Tibetan medicine, global health, migration, and social change. Her 
most recent book is The Ends of Kinship: Connecting Himalayan Lives between Nepal and New York (University of Washington Press, 2020).

Born in Mustang, Nepal, and educated in Kathmandu and the United States, Nawang T. Gurung is a consultant, translator, independent researcher, and social entrepreneur based in New York City. He has worked extensively with the Endangered Language Alliance and is founder and director of the Yulha Fund.

Ross Perlin is a linguist, writer, and translator focused on exploring and supporting linguistic diversity. He is a codirector of the Endangered Language Alliance in New York City.

Maya Daurio is a PhD student in anthropology at the University of British Columbia interested in linguistic mobility and boundary-making, and in developing innovative cartographic and spatial analysis methods for documenting, displaying, and exploring the distribution of languages and people in the urban settings of Kathmandu and New York City.

Daniel Kaufman is an assistant professor of linguistics at Queens College, City University of New York, specializing in Austronesian languages and a founding codirector of the Endangered Language Alliance, a nonprofit organization working to document and sustain languages spoken by Indigenous and immigrant communities in New York City.

Mark Turin is an associate professor at the University of British Columbia, Vancouver, Canada, cross-appointed in the Institute for Critical Indigenous Studies and the Department of Anthropology. He writes and teaches on language reclamation, revitalization, documentation, and conservation; language mapping, policies, and politics; and digital tools and technology.

Kunchog Tseten is a Tibetan physician and Tibetan language instructor originally from the Repgong region of Amdo (Qinghai Province, China). He earned his medical degree from the Qinghai Tibetan Medical College and a degree in Chinese medicine from the Pacific College of Oriental Medicine in New York.

\section{Bibliography}

Adams, Vincanne, ed. 2015. Metrics: What Counts in Global Health. Durham, NC: Duke University Press.

Akram, Ali, and Andrew Caruana Galizia. 2020. "Nepal Faces a Crisis as COVID-19 Stems the Flow of Remittances." World Economic Forum, June 16, 2020. https://www .weforum.org/agenda/2020/o6/nepal-faces-a-crisis-as-covid-19-stems-the-flow-of -remittances/.

Almukhtar, Sarah, Aliza Aufrichtig, Anne Barnard, Matthew Bloch, Weiyi Cai, Julia Calderone, Keither Collins, et al. 2021. "New York City Coronavirus Map and Case 
Count." Infographic, New York Times, updated January 5, 2021. https://www.nytimes .com/interactive/2020/nyregion/new-york-city-coronavirus-cases.html.

Appadurai, A. 1995. "The Production of Locality." In Counterworks: Managing the Diversity of Knowledge, edited by Richard Fardon, 204-25. London: Routledge.

Arya, Pasang Yonten, and Jan M. A. van der Valk. 2020. "A Conversation on the Causes of Covid-19 with a Senior Tibetan Doctor Living in Lockdown in Milan." Fieldsights (blog of the Society for Cultural Anthropology), "Hotspots" section, June 23, 2020. https://culanth.org/fieldsights/a-conversation-on-the-causes-of-covid-19-with-a -senior-tibetan-doctor-living-in-lockdown-in-milan.

Banerjee, Madhulika. 2020. "Ayurveda and Covid-19: The Politics of Knowledge Systems, Yet Again." Fieldsights (blog of the Society for Cultural Anthropology), "Hotspots" section, June 23, 2020. https://culanth.org/fieldsights/ayurveda-and -covid-19-the-politics-of-knowledge-systems-yet-again.

Banerjee, Subhabrata Bobby. 2011. "Voices of the Governed: Towards a Theory of the Translocal." Organization 18, no. 3: 323-44.

Behbahani, Sara, Cynthia A. Smith, Michelly Carvalho, Christopher J. Warren, Micah Gregory, and Nicole A. Silva. 2020. "Vulnerable Immigrant Populations in the New York Metropolitan Area and COVID-19: Lessons Learned in the Epicenter of the Crisis.” Academic Medicine 95, no. 12: 1827-30.

Bonifacio, Ayendy. 2020. "For Many Immigrants, an Even Greater Risk." New York Times, April 25, 2020. https://www.nytimes.com/2020/o4/25/opinion/immigrants -coronavirus.html.

Buchanan, Larry, Jugal K. Patel, Brian M. Rosenthal, and Anjali Singhvi. 2020. "A Month of Coronavirus in New York City: See the Hardest-Hit Areas." New York Times, April 1, 2020. https://www.nytimes.com/interactive/2020/04/o1/nyregion/nyc -coronavirus-cases-map.html.

Chenagtsang, Nida, Robert Thurman, Eric Rosenbush, Lobsang Tsering, and Ben Joffe. 2020. "Tibetan Medical Approaches to Understanding COVID-19." Panel discussion. In Sowa Rigpa \& Covid 19, webinar hosted by Pure Land Farms in Topanga, CA, April 9, 2020. https://purelandfarms.com/programs/2020/4/9/sowa-rigpa-covid-19.

Correal, Annie, and Andrew Jacobs. 2020. "A Tragedy Is Unfolding': Inside New York's Virus Epicenter." Chicago Tribune, April 9, 2020. https://www.chicagotribune.com/ coronavirus/ct-nw-nyt-tragedy-new-york-virus-epicenter-20200410-mktotr4gd5ftz mklhhc4iq4eem-story.html.

Craig, Sienna R. 2020. The Ends of Kinship: Connecting Himalayan Lives between Nepal and New York. Seattle: University of Washington Press.

Craig, Sienna R., and Vincanne Adams. 20o8. "Global Pharma in the Land of Snows: Tibetan Medicines, SARS, and Identity Politics across Nations.” Asian Medicine 4, no. 1: 1-28.

Craig, Sienna R., and Barbara Gerke. 2016. "Naming and Forgetting: Sowa Rigpa and the Territory of Asian Medical Systems." Medicine Anthropology Theory 3, no. 2: 87-122. 
Craig, Sienna R., Barbara Gerke, and Jan M. A. van der Valk. 2020a. "Asian Medicines, COVID-19 and the Politics of Science: An Unpublished Letter to the Editor of Nature." Somatosphere, Advocacy Letters series, August 14, 2020. http://somato sphere.net/2020/an-unpublished-letter-to-the-editor-of-nature.html/.

Craig, Sienna R., Barbara Gerke, and Jan M. A. van der Valk. 2020b. "Responding to an Unfolding Pandemic: Asian Medicines and Covid-19." Fieldsights (blog of the Society for Cultural Anthropology), "Hotspots" section, June 23, 2020. https:// culanth.org/fieldsights/series/responding-to-an-unfolding-pandemic-asian -medicines-and-covid-19.

Cuomu, Mingji. 2020. "Covid-19 from Tibetan Medical and Cultural Perspectives: A Report from Lhasa." Fieldsights (blog of the Society for Cultural Anthropology), "Hotspots" section, June 23, 2020. https://culanth.org/fieldsights/covid-19-from -tibetan-medical-and-cultural-perspectives-a-report-from-lhasa.

Daurio, Maya, Sienna R. Craig, Daniel Kaufman, Ross Perlin, and Mark Turin. 2020. "Subversive Maps: How Digital Language Mapping Can Support Biocultural Diversity_and Help Track a Pandemic." Terralingua, May 19, 2020. https://terra lingua.org/langscape_articles/subversive-maps-how-digital-language-mapping -can-support-biocultural-diversity/.

Endangered Language Alliance. n.d.a. https://elalliance.org/.

Endangered Language Alliance. n.d.b. "Maps." https://elalliance.org/programs/maps/.

Endangered Language Alliance. n.d.c. "Voices of the Himalaya." https://elalliance.org/ languages/himalaya/.

Etzold, Benjamin. 2017. "Mobility, Space and Livelihood Trajectories: New Perspectives on Migration, Translocality and Place-Making for Livelihood Studies." In Livelihoods and Development, edited by Leo de Haan, 44-68. Leiden: Brill.

Freytas-Tamura, Kimiko de. 2020. "Just 700 Speak This Language (50 in the Same Brooklyn Building).” New York Times, January 13, 2020. https://www.nytimes .com/2020/o1/o7/nyregion/rare-languages-seke-vlashki-wakhi.html.

Gerke, Barbara. 2017. "Tibetan Precious Pills as Therapeutics and Rejuvenating Longevity Tonics." History of Science in South Asia 5, no. 2: 204-33.

Gerke, Barbara. 2020. "Sowa Rigpa in Lockdown: On the Potency and Politics of Prevention." Fieldsights (blog of the Society for Cultural Anthropology), "Hotspots" section, June 23, 2020. https://culanth.org/fieldsights/ sowa-rigpa-in-lockdown-on-the-potency-and-politics-of-prevention.

Gill, Peter. 2020. “Coronavirus Severs Nepal's Economic Lifeline." The Diplomat, April 20, 2020. https://thediplomat.com/2020/04/coronavirus-severs-nepals -economic-lifeline/.

Goodman, J. David. 2020. "How Will We Know a 2nd Virus Wave Has Arrived in N.Y.C.?" New York Times, October 8, 2020. https://www.nytimes.com/2020/10/o8/nyregion/ nyc-coronavirus-second-wave.html. 
Grange, Lucile, Philippe Guilpain, Marie-Elise Truchetet, Jean-Luc Cracowski, and French Society of Pharmacology and Therapeutics. 2020. "Challenges of Autoimmune Rheumatic Disease Treatment during the COVID-19 Pandemic: A Review." Therapies 75, no. 4: 335-42. https://www.doi.org/10.1016/j.therap.2020.06.013.

Gurung, Nawang, Ross Perlin, Daniel Kaufman, Mark Turin, and Sienna R. Craig. 2018. "Orality and Mobility: Documenting Himalayan Voices in New York City." Verge: Studies in Global Asias 4, no. 2: 64-80.

Gurung, Nawang Tsering, Ross Perlin, Mark Turin, Sienna R. Craig, Maya Daurio, and Daniel Kaufman. 2020. "Himalayan New Yorkers Tell Stories of COVID-19." Nepali Times, June 6, 2020. https:/www.nepalitimes.com/here-now/himalayan -new-yorkers-tell-stories-of-covid-19/.

Han, Chaoqun, Caihan Duan, Shengyan Zhang, Brennan Spiegel, Huiying Shi, Weijun Wang, Lei Zhang, et al. 2020. "Digestive Symptoms in COVID-19 Patients with Mild Disease Severity: Clinical Presentation, Stool Viral RNA Testing, and Outcomes." American Journal of Gastroenterology 115, no. 6: 916-23.

Hanson, Marta. 2010. "Conceptual Blind Spots, Media Blindfolds: The Case of sARs and Traditional Chinese Medicine." In Health and Hygiene in Chinese East Asia: Policies and Publics in the Long Twentieth Century, edited by Angela Ki Che Leung and Charlotte Furth, 228-54. Durham, NC: Duke University Press.

Herzfeld M. 2015. "The Village in the World and the World in the Village: Reflections on Ethnographic Epistemology." Critique of Anthropology 35, no. 3: 338-43.

Hogan, Gwynne. 2020. "Staggering Surge of NYers Dying in Their Homes Suggests City Is Undercounting Coronavirus Fatalities." Gothamist, April 7, 2020. https:// gothamist.com/news/surge-number-new-yorkers-dying-home-officials-suspect -undercount-covid-19-related-deaths.

Holpuch, Amanda. 2020. "How Did an NYPD Officer from Tibet End Up Accused of Spying for China?” Guardian, September 29, 2020. https://www.theguardian.com/ world/2020/sep/29/tibetan-diaspora-spying-new-york-china.

Hong, Nicole. 2020. "N.Y.P.D. Officer Is Accused of Spying on Tibetans for China." New York Times, September 21, 2020. https://www.nytimes.com/2020/o9/21/nyregion/ nypd-china-tibet-spy.html.

Jordan, Miriam. 2020. “We're Petrified': Immigrants Afraid to Seek Medical Care for Coronavirus." New York Times, May 12, 2020. https://www.nytimes.com/2020/o3/18/ us/coronavirus-immigrants.html.

Jordan, Miriam, and Richard A. Oppel Jr. 2020. "For Latinos and Covid-19, Doctors Are Seeing an 'Alarming' Disparity." New York Times, May 7, 2020. https://www.nytimes .com/2020/05/o7/us/coronavirus-latinos-disparity.html.

Kaplan, Joshua. 2020. "Hospitals Have Left Many COVID-19 Patients Who Don't Speak English Alone, Confused and without Proper Care." ProPublica, March 31, 2020. 
https://www.propublica.org/article/hospitals-have-left-many-covid19-patients -who-dont-speak-english-alone-confused-and-without-proper-care.

Kaufman, Daniel, and Ross Perlin. Forthcoming. "Invisibilization of Indigenous Languages in Urban Centers." In Global Language Justice, edited by Lydia Liu. New York: Columbia University Press.

Kloos, Stephan. 2017. "The Pharmaceutical Assemblage: Rethinking Sowa Rigpa and the Herbal Pharmaceutical Industry in Asia." Current Anthropology 58, no. 6: 693-717.

Kunde Institute. n.d. "Research and Education." https://www.kundewellness.org/ research--education.html.

Language Mapping. n.d. Vancouver, BC: University of British Columbia; New York: Endangered Language Alliance. https://languagemapping.org/.

Levitt, Peggy, and Nina Glick Schiller. 2004. "Conceptualizing Simultaneity: A Transnational Field Perspective on Society." International Migration Review 38, no. 3: 1002-39.

Lopez, Miriam Magaña, and Seth M. Holmes. 2020. "Raids on Immigrant Communities During the Pandemic Threaten the Country's Public Health." American Journal of Public Health 100, no. 7: 958-59.

Lynteris, Christos. 2020. "Sinophobia, Epidemics, and Interspecies Catastrophe." Fieldsights (blog of the Society for Cultural Anthropology), "Hotspots" section, June 23, 2020. https://culanth.org/fieldsights/sinophobia-epidemics-and-inter species-catastrophe.

Mason, Katherine A. 2016. Infectious Change: Reinventing Chinese Public Health after an Epidemic. Stanford, CA: Stanford University Press.

McGrath, William A. 2020. "Quarantine and Expulsion in Early Tibet: Reflections on the Padmasambhava Legend in the Age of the Coronavirus." Fieldsights (blog of the Society for Cultural Anthropology), "Hotspots" section, June 23, 2020. https:// culanth.org/fieldsights/quarantine-and-expulsion-in-early-tibet-reflections-on -the-padmasambhava-legend-in-the-age-of-the-coronavirus.

Mukharji, Projit Bihari. 2012. "The 'Cholera Cloud' in the Nineteenth-Century 'British World': History of an Object-Without-an-Essence." Bulletin of the History of Medicine 86, no. 3: 303-32.

Non-Resident Nepali Association National Coordination Council USA, New York Chapter. n.d. Urgent Nepali Aid Network for Covidig. Facebook group. https://www .facebook.com/groups/519756348973340/.

Payyappallimana, Unnikrishnan. 2020. "Doctors at the Borders: Ayurveda's Encounter with Public Health and Epidemics." Fieldsights (blog of the Society for Cultural Anthropology), "Hotspots" section, June 23, 2020. https://culanth.org/fieldsights/ doctors-at-the-borders-ayurvedas-encounter-with-public-health-and-epidemics.

Peng Weihua, and Elisabeth Hsu. 2020. "Three Qinghao Formulae for Treating Epidemics (wen yi)." Fieldsights (blog of the Society for Cultural Anthropology), 
"Hotspots" section, June 23, 2020. https://culanth.org/fieldsights/three-qinghao -formulae-for-treating-epidemics-wen-yi.

Pettigrew, Luisa M., Stephanie Kumpunen, and Nicholas Mays. 2020. "Primary Care Networks: The Impact of COVID-19 and the Challenges Ahead." British Medical Journal 370: M3353.

Pfaff-Czarnecka, Joanna, and Gérard Toffin, eds. 2011. The Politics of Belonging in the Himalayas: Local Attachments and Boundary Dynamics. Thousand Oaks, CA: SAGE Publications.

Ploberger, Florian. 2020. "Covid-19 From the Perspective of TCM Physicians in GermanSpeaking Countries." Fieldsights (blog of the Society for Cultural Anthropology), "Hotspots" section, June 23, 2020. https://culanth.org/fieldsights/covid-19-from-the -perspective-of-tcm-physicians-in-german-speaking-countries.

Ross, Jonathan, Chanelle M. Diaz, and Joana L. Starrels. 2020. "The Disproportionate Burden of COVID-19 for Immigrants in the Bronx, New York." JAMA Internal Medicine 180, no. 8:1043-44. https://www.doi.org/10.1001/jamainternmed.2020.2131.

Ruiz-Grossman, Sarah. 2020. "Study Shows COVID-19's Devastating Impact on Black Immigrant Domestic Workers." Huffington Post, June 18, 2020. https://www.huffing tonpost.ca/entry/black-immigrant-domestic-workers-coronavirus_n_5eebabd6c 5b69bcc41d67e52?ri18n=true.

Sharma, Gopal. 2020. "Nepal Families Face Hunger, Skip Meals as Pandemic Hits Remittances." Reuters, June 29, 2020. https://www.reuters.com/article/us-health -coronavirus-nepal-idUSKBN24104A.

Sheldon, Victoria. 2020. "Covid-19 in Kerala: Nature Cure, Social Media, and Subaltern Health Activism." Fieldsights (blog of the Society for Cultural Anthropology), "Hotspots" section, June 23, 2020. https://culanth.org/fieldsights/covid-19-in-kerala -nature-cure-social-media-and-subaltern-health-activism.

Sherpa, Pasang Yangjee. 2019. "Sustaining Sherpa Language and Culture in New York." Book 2.o 9, no. 1-2: 19-29.

Shneiderman, Sara. 2015. Rituals of Ethnicity: Thangmi Identities between Nepal and India. Philadelphia: University of Pennsylvania Press.

Slavitt, Andy. 2020. "The COVID-19 Pandemic Underscores the Need to Address Structural Challenges of the US Health Care System." JAMA Health Forum, July 2, 2020. http://doi.org/10.1001/jamahealthforum.2020.0839.

Stein, Robin, and Caroline Kim. 2020. "People Are Dying': 72 Hours inside a N.Y.C. Hospital Battling Coronavirus." New York Times, March 25, 2020. Video, 5:33. https://www.nytimes.com/video/nyregion/100000007052136/coronavirus-elmhurst -hospital-queens.html.

Suleymanova, Radmilla. 2020. "Remittances, a Vital Financial Lifeline, Are Being Squeezed." Al Jazeera, June 16, 2020. https://www.aljazeera.com/economy/2020/6/ 16/remittances-a-vital-financial-lifeline-are-being-squeezed. 
Sun Xin, and Elisabeth Hsu. 2020. "Translation of Beijing's Recommendations for Traditional Chinese Medicine (TCM) Treatment of Covid-19." Fieldsights (blog of the Society for Cultural Anthropology), "Hotspots" section, June 23, 2020. https:// culanth.org/fieldsights/translation-of-beijings-recomendations.

Tibetan Nurses Association of New York and New Jersey. 2020. Tibetan Nurses Asso. Pandemic \& Community Outreach. GoFundMe fundraiser, started March 29, 2020. https://www.gofundme.com/f/ryg9tg-a-cause-i-care-about-needs-help.

Tidwell, Tawni. 2020. "Covid-19 and Tibetan Medicine: An Awakening Tradition in a New Era of Global Health Crisis." Fieldsights (blog of the Society for Cultural Anthropology), "Hotspots" section, June 23, 2020. https://culanth.org/fieldsights/ covid-19-and-tibetan-medicine-an-awakening-tradition-in-a-new-era-of-global -health-crisis.

Tidwell, Tawni, and Khenrab Gyamtso. 2021. "Tibetan Medical Paradigms for the SARSCoV-2 Pandemic: Understanding COVID-19, Microbiome Links, and Its Sowa Rigpa Nosology." Asian Medicine 16, no. 1: 89-127.

Tomar, Koyna. 2020. "Ayurveda in the (Mis)Information Age." Fieldsights (blog of the Society for Cultural Anthropology), "Hotspots" section, June 23. https://culanth.org/ fieldsights/ayurveda-in-the-misinformation-age.

Tsamakis, Konstantinos, Maria Gavriatopoulou, Dimitrios Schizas, Athina Stravodimou, Aikaterini Mougkou, Dimitrios Tsiptsios, Basileios Sioulas, et al. 2020. "Oncology During the COVID-19 Pandemic: Challenges, Dilemmas and the Psychosocial Impact on Cancer Patients." Oncology Letters 20, no. 1:441-47. http://doi.org/10.3892/ ol.2020.11599.

Tseten, Kunchog. 2020. Dr. Kunchog (Amdo). Audio diary. New York: Endangered Language Alliance. https://soundcloud.com/elalliance/sets/dr-kunchog-tseten-amdo -diary.

Turin, Mark. 2012. "New York City." In Our Language in Your Hands, on BBC Radio 4 Extra, December 17, 2012. Podcast, audio, 29:44. https://www.bbc.co.uk/programmes/ boipbhw3.

Turin, Mark. 2013. "Globalization Helps Preserve Endangered Languages." YaleGlobal Online, December 3, 2013. https://yaleglobal.yale.edu/content/globalization-helps -preserve-endangered-languages.

Venugopal, Arun. 2020. "New Yorkers Sharing Crowded Apartments Struggle with Coronavirus Quarantines and Social Distancing." Gothamist, April 2, 2020. https:// gothamist.com/news/new-yorkers-sharing-crowded-apartments-strugglecoronavirus-quarantines-social-distancing.

Williams, Siân, and Ionna Tsiligianni. 2020. "COVID-19 Poses Novel Challenges for Global Primary Care." npj Primary Care Respiratory Medicine 3o, no. 3o. https://doi. org/10.1038/s41533-020-0187-x.

Zhan, Mei. 20o9. Other-Worldly: Making Chinese Medicine through Transnational Frames. Durham, NC: Duke University Press. 